\title{
"É uma escola do campo, e agora?": crônicas como um produto educacional
}

"It's a rural school, and now?": chronicles as an educational product

\author{
Larissa Gehrinh Borges * \\ Línlya Sachs ${ }^{* *}$
}

\section{Resumo}

Este artigo apresenta o Produto Educacional "É uma escola do campo, e agora?", realizado no formato de um livreto com 11 crônicas, narradas por uma personagem fictícia, Maria, professora de Matemática, com um contrato temporário em uma escola do campo. A pesquisa, em nível de mestrado, que fomentou essa produção foi realizada em uma escola do campo localizada em área de Reforma Agrária do estado do Paraná, com uma proposta curricular específica (Plano de Estudos). Com a pesquisa, procuramos compreender se essa proposta se efetivava (ou não) ali mais especificamente, em aulas de Matemática do Ensino Fundamental II e do Ensino Médio. A opção por criar um livreto de crônicas foi fundamentada nos referenciais teóricos - em especial, a Etnomatemática e alguns conceitos do Modelo dos Campos Semânticos - e metodológicos da pesquisa.

Palavras-chave: Educação Matemática. Educação do Campo. Escolas itinerantes. Crônicas. Produto Educacional.

\section{Abstract}

This paper presents the educational product "Is it a rural school, and now?", in the format of a book with 11 chronicles, narrated by a fictional character, Maria, a Mathematics teacher, with a temporary contract in a rural school. The research, at the master's level, that promoted the production was carried out in a rural school located in area of Agrarian Reform of the state of Paraná, with a specific curricular proposal. We research whether this proposal was effective (or not) - specifically, in Mathematics classes. The option to create a chronic book was based on the theoretical references - in particular, on an Ethnomathematics and on some concepts of the Model of Semantic Fields - and on methodological aspects of the research.

Keywords: Mathematics Education. Rural Education. Itinerant schools. Chronic. Educational Product.

* Mestre em Ensino de Matemática pela Universidade Tecnológica Federal do Paraná (UTFPR), Londrina e Cornélio Procópio, Paraná, Brasil. E-mail: larissageborges@hotmail.com.

* Doutora em Educação Matemática pela Universidade Estadual Paulista "Júlio de Mesquita Filho" (Unesp). Docente da Universidade Tecnológica Federal do Paraná (UTFPR), Cornélio Procópio, Paraná, Brasil. E-mail: linlyasachs@yahoo.com.br. 


\section{Abrindo o livro...}

\section{Crônica 1: Tudo novo de novo}

Era um dia qualquer de maio de 2016, mas não para mim. E aí você me pergunta, quem é você? Desculpe a falta de educação, meu nome é Maria e sou professora de matemática. Foi a primeira vez que eu fui à nova escola em que eu trabalharia. Para nós, professores PSS ${ }^{1}$, é comum mudarmos de escola com uma certa frequência, mas sempre bate aquele friozinho na barriga. Como será que vai ser lá? Quem serão os meus novos colegas de trabalho, ou meus alunos... bate aquela ansiedade. Aquela mudança foi diferente.

Era uma escola do campo, localizada em um assentamento da reforma agrária. A primeira vez que fui até a nova escola, fui com meu carro. Saí de casa por volta das 7 h, e o mapa dizia que a distância entre a minha casa e o distrito em que a escola se localizava era de, mais ou menos, $55 \mathrm{~km}$. Cheguei ao distrito tranquilamente, e então, como o GPS não reconhecia a escola, pedi informação em uma vendinha. É só a senhora seguir pela estrada de terra que fica no fim dessa rua, até avistar os eucaliptos, depois disso é só virar à direita que vai dar na escola, eles disseram. Ah, então é tranquilo. Não tem erro! Pobre inocência a minha pensar que seria tão simples assim. Rodei, rodei, rodei e nada de ver esses tais eucaliptos. Mas gente, eucalipto não é aquela árvore imensa? Que dá para ver de longe? Será que tem outro tipo de eucalipto, e ninguém nunca me apresentou? Já sei! Vou ligar para alguém me ajudar. Missão impossível! Nada de sinal por lá. Esperar alguém passar? Mas e se não passar? Já pensou se fura um pneu aqui? Deus me livre. Achei melhor voltar. Continuei rodando até encontrar uma casa. Parei, e me deram a informação de que era para continuar reto e subir a primeira estrada à esquerda. Confesso que não resisti e perguntei se lá havia eucaliptos. A moça me disse que sim, mas que eram recém-plantados e, portanto,

1 PSS significa "processo seletivo simplificado", na Secretaria de Estado da Educação do Paraná. A referência é feita aos professores que não são concursados, mas contratados por meio desse processo. A distribuição de aulas da rede estadual de ensino ocorre, primeiramente, entre os professores concursados e, em caso de haver aulas remanescentes, são atribuídas aos professores habilitados e classificados pelo PSS. 
eram bem pequenos. Ufa! Pelo menos não inventaram um outro eucalipto. $O$ moço da venda só esqueceu de me passar esse detalhe. Depois de um bom tempo, consegui chegar à escola.

Eu nunca havia dado aula em uma escola como essa. Uma escola que, apenas ao observar sua estrutura física, já demonstrava que era uma escola de luta. Luta para se manter de pé, funcionando, atendendo aquela gente. Uma escola diferente de tudo o que já havia visto antes nas minhas andanças entre uma escola e outra.

Eu estava acostumada com escolas que possuem grandes muros para que os alunos não tivessem contato com as pessoas de fora ou fossem embora durante as aulas, com prédios de alvenaria, com as crianças todas de uniforme, com inspetores de alunos controlando até mesmo quando iam ao banheiro. Nada disso acontece nessa nova escola.

Fiquei boquiaberta quando por lá cheguei. A começar pelo fato de que essa escola não tem muros. Entra quem quer, e sai também. Em uma conversa, durante um café na sala dos professores, com um dos professores que também é morador da comunidade, ele me disse que a escola como é hoje foi construída pelos próprios moradores do assentamento, e que muitos desses moradores são pais dos alunos que a frequentam. Na hora pensei nas escolas urbanas, as quais eu estava acostumada a frequentar. Lá, os pais mal vão às reuniões, enquanto, ali, os pais é que construíram a escola para que seus filhos pudessem estudar.

Ainda durante esse café, o professor me disse:

- Nossa escola não tem muros, pois todos os que querem aprender ou contribuir de alguma forma são bem-vindos.

Fiquei com aquilo na cabeça. Quanta ironia! E há quem diga que o campo é que é sinônimo de atraso. Deu a impressão de que a escola não é só dos alunos, diretor e professores, mas de toda a comunidade. Bom, se eu estou indo da minha cidade para dar aula lá na escola, devo estar contribuindo de alguma forma e acho que sou bem-vinda, eu espero. Mas... como será trabalhar em um lugar tão diferente assim? 
Assim inicia o Produto Educacional "De professor para professor: escola do campo, e agora?", resultado de uma pesquisa de mestrado profissional em Ensino de Matemática, desenvolvida na Universidade Tecnológica Federal do Paraná, multicâmpus Londrina e Cornélio Procópio².

Esse Produto Educacional se constitui em um livreto composto por 11 crônicas fictícias - sendo a primeira delas apresentada acima -, que foram escritas a partir da realidade vivenciada durante a pesquisa em uma escola do campo.

A escolha pela elaboração desse Produto Educacional como um conjunto de crônicas deu-se pelas opções teóricas e metodológicas da pesquisa, que explicamos adiante. A proposta foi estabelecer um espaço comunicativo com o leitor - possivelmente, um professor de matemática de uma escola do campo, mas que não seja do campo -, por meio de crônicas que trouxessem impressões pessoais, reflexões, acontecimentos e inquietações da narradora. Para isso, foi criada uma personagem, a professora Maria, já com alguns anos de carreira e que, de repente, se depara com uma escola diferente, em diversos aspectos, daquilo que já havia vivenciado em sua profissão. Nessa escola, ela passa por situações, aventuras, dificuldades e experiências que a fazem refletir sobre sua prática docente. É uma escola do campo, e agora?

\section{Que livro é esse?}

A pesquisa que originou esse Produto Educacional - relatada na dissertação de mestrado "Saberes matemáticos nas escolas itinerantes: complexos de estudo" (BORGES, 2017) - foi realizada entre os anos de 2016 e 2017, com objetivo de compreender e apresentar a organização das escolas itinerantes do Paraná e sua proposta curricular, chamada Plano de Estudos.

2 Essa pesquisa de mestrado foi realizada pela primeira autora deste artigo, sendo orientada pela segunda autora. 
Essas escolas itinerantes são escolas localizadas em acampamentos ${ }^{3}$ do Movimento dos Trabalhadores Rurais Sem Terra (MST), no Paraná, e recebem esse nome, pois fazem itinerância, acompanhando possíveis mudanças de localização dos acampados, de um espaço a outro. Eventualmente, na transformação de acampamento em assentamento ${ }^{4}$, é possível que a escola deixe de ser itinerante, mas continue seguindo os preceitos dessas escolas, inclusive sua organização curricular. É o caso do Colégio Estadual Maria Aparecida Rosignol Franciosi - local em que foi realizada a pesquisa.

Essa escola está no assentamento Eli Vive, situado no distrito de Lerroville, pertencente ao município de Londrina, Paraná. São, na verdade, dois assentamentos: Eli Vive I e Eli Vive II, que se referem às antigas Fazenda Guairacá e Pininga, respectivamente. Em 1991, os integrantes do MST ocuparam essa área durante um período de três meses, porém foram violentamente forçados a sair. Em 2008, por temer novas ocupações, os proprietários a ofereceram ao Instituto Nacional de Colonização e Reforma Agrária (INCRA) e, no início de 2009, cerca de 120 famílias iniciaram as ocupações, enquanto ainda ocorriam as negociações entre os proprietários da terra e o INCRA (COLÉGIO ESTADUAL MARIA APARECIDA ROSIGNOL FRANCIOSI, 2015).

Para suprir a necessidade das crianças em idade escolar, as primeiras famílias que ocuparam a fazenda construíram duas salas de aula com lona preta e taquara, começando assim a construção da escola, que, posteriormente, foi ampliada. Em agosto de 2009, ela se constituiu como uma escola itinerante, sendo chamada de Escola Itinerante Maria Aparecida Rosignol Franciosi (COLÉGIO ESTADUAL MARIA APARECIDA ROSIGNOL FRANCIOSI, 2015).

3 "Acampamento é um espaço de luta e resistência. É a materialização de uma ação coletiva que torna pública a intencionalidade de reivindicar o direito à terra para produção e moradia. O acampamento é uma manifestação permanente para pressionar os governos na realização da Reforma Agrária" (CALDART et al., 2012, p. 23).

${ }^{4}$ Assentamento é quando ocorre a consolidação da Reforma Agrária, quando as terras são conquistadas pelos acampados. Assim, um “(...) número expressivo de trabalhadores que participaram de processos de ocupação de terra deixaram de ser acampados para se tornarem, num momento seguinte, assentados" (CALDART et al., 2012, p. 110). 
Em 2012, a escola deixa de ser itinerante (com a transformação do acampamento em assentamento) e passa a ser denominada Colégio Estadual Maria Aparecida Rosignol Franciosi, oferecendo Educação Infantil, Ensino Fundamental e Ensino Médio. No ano de 2016, passa por uma nova reestruturação: o município de Londrina torna-se responsável pelo oferecimento da Educação Infantil e dos anos iniciais do Ensino Fundamental, com a criação da Escola Municipal do Campo Trabalho e Saber, que divide a estrutura física com a instituição estadual.

Apesar das mudanças, as escolas - o Colégio Estadual Maria Aparecida Rosignol Franciosi e a Escola Municipal do Campo Trabalho e Saber - procuram manter algumas características das escolas itinerantes, como a organização curricular presente no Plano de Estudos (MOVIMENTO DOS TRABALHADORES RURAIS SEM TERRA, 2013), baseada em complexos de estudo ${ }^{5}$, ciclos de formação humana, avaliações realizadas com pareceres descritivos, e não notas, sem reprovações, mas com classes intermediárias ${ }^{6}$.

Nessa escola, foi desenvolvida nossa pesquisa. Procuramos compreender se a proposta curricular, presente no Plano de Estudos, se efetivava (ou não) ali mais especificamente, em aulas de Matemática do Ensino Fundamental II e do Ensino Médio.

Para isso, seguimos algumas indicações de pesquisas etnográficas - sem que a pesquisa assumisse completamente esse viés, visto que isso requereria inserção total no ambiente de estudo.

Após um contato inicial, apresentando para a coordenação e a direção da escola o objetivo da pesquisa e obtendo autorização para realizá-la, foram feitas visitas semanais à escola. Uma van saía às $6 \mathrm{~h} 30$ da manhã da região central do município de Londrina, transportando grande parte dos professores para a escola,

5 Os complexos de estudo são unidades curriculares do Plano de Estudos, organizados a partir de porções da realidade (por exemplo: luta pela reforma agrária; manejo de ecossistemas; venda/comercialização de produtos) que se relacionam com a vida nos acampamentos e assentamentos da Reforma Agrária. Os nomes "complexos de estudo" e "Plano de Estudos" foram inspirados na proposta da Escola-Comuna, da União Soviética (FREITAS, 2009).

6 Mais informações a respeito da organização do trabalho pedagógico nas escolas itinerantes podem ser encontradas em Sapelli, Freitas e Caldart (2015). 
chegando lá por volta de 7h40; após as aulas do período da tarde, às 17h40, a van retornava à sede do município, chegando por volta de 19h. Obtivemos autorização da Secretaria Municipal de Educação de Londrina para que, também, utilizássemos esse transporte - já que não havia transporte público que fizesse todo esse trajeto para realizarmos o deslocamento.

Durante o período de permanência na escola, foram acompanhadas as aulas de Matemática de uma professora. Nos momentos em que não estávamos em aula, pudemos frequentar os diversos espaços escolares: a sala dos professores, a biblioteca, outras salas de aula, o refeitório, a secretaria e o pátio. Vivíamos e convivíamos (com os estudantes, os professores, a equipe administrativa e demais funcionários) naquele ambiente escolar.

A cada visita realizada - de um total de 12 -, alimentávamos um diário de pesquisa, que foi um importante material de análise. O diário era redigido após cada visita, porém, durante o decorrer do dia na escola, algumas pequenas anotações eram feitas para auxiliar nesse processo de elaboração, com palavraschave que remetessem a alguma situação em especial, para, depois, registrar com calma.

O diário de pesquisa - importante instrumento de pesquisas etnográficas -, no nosso caso, era um misto de tecnologias: papel e caneta para anotar os itens principais durante a estadia na escola; um celular smartphone para fotografar a própria escola e materiais compartilhados pelos professores; e um software de digitação de texto para melhor descrever o que foi vivenciado na escola, após o retorno das visitas. Como afirmam Altrichter e Holly (2015, p. 80, grifos dos autores), o diário de pesquisa pode conter:

- dados obtidos mediante observação, entrevistas e conversas informais, discussões entremeadas e grupos de interesse; - outros "objetos achados", como fotografias, cartas, vídeos, sites, wikis, blogs; • informação contextual sore as formas e os meios pelos quais esses dados foram colhidos; - reflexões sobre métodos de pesquisa ideias, exemplos e planos para passos posteriores da pesquisa.

Além do diário, foram realizadas gravações de áudio das aulas de matemática acompanhadas. No total, foram 5 horas e 35 minutos de gravações. 
Durante o desenvolvimento da pesquisa, não houve um roteiro préelaborado sobre os passos que se trilharia. Cada um deles era estipulado na própria caminhada. Garnica (2015, p. 38) diz "que uma metodologia não é algo estático, mas um arsenal de possibilidades sempre em construção", e assim foi com esse trabalho.

Os pressupostos teóricos dessa pesquisa foram, principalmente, a Etnomatemática e alguns conceitos do Modelo dos Campos Semânticos.

Por um lado, a Etnomatemática considera como conhecimento o que, rotineiramente, não é reconhecido como tal. Knijnik (2000), por exemplo, ressalta a existência de outras matemáticas:

[...] para sermos mais precisos, deveríamos dizer que aquilo que chamamos tradicionalmente de Matemática é a Matemática acadêmica. Na perspectiva da Etnomatemática, existem também outras formas de produzir significados matemáticos, outras formas que são igualmente Etnomatemáticas, pois manifestações simbólicas de grupos culturais.

Como afirma Sachs (2017, p. 314), a Etnomatemática possibilita reconhecer e registrar saberes: "Sem isso, não é possível propor diálogo entre conhecimentos; sem outros conhecimentos, mantém-se o monólogo que há tempos se vê na escola - e, mais ainda, em aulas de matemática".

Assim, a Etnomatemática abriu, para nós, possibilidades de questionar, politicamente, a valorização - ou a desvalorização - dada aos conhecimentos (matemáticos, em particular), considerando suas complexidades e respeitando suas especificidades.

É neste sentido que considero a importância do pensamento etnomatemático, que problematiza a cientificidade, a neutralidade e assepsia da Matemática acadêmica e traz à cena as "outras" Matemáticas, usualmente silenciadas na escola, enquanto produção cultural de grupos não hegemônicos (KNIJNIK, 2000).

Por outro lado, o Modelo dos Campos Semânticos aborda os conceitos de conhecimento e de legitimidade, recolocando-os em uma discussão educacional que nos interessa.

Para Lins (2012, p. 12), diferentemente de definições mais comumente utilizadas, "um conhecimento consiste em uma crença-afirmação (o sujeito enuncia algo em que acredita) junto com uma justificação (aquilo que o sujeito 
entende como Ihe autorizando a dizer o que diz)". Desse modo, o conhecimento existe a partir de uma enunciação (crença-afirmação) e de uma justificação:

A justificação deve ser parte constitutiva de um conhecimento (e não apenas um acessório para se verificar se o sujeito tem o direito de dizer que conhece isto ou aquilo). É assim porque de outro modo não é possível distinguir o conhecimento de uma criança e de um matemático quando dizem " $2+4=4+2$ ", e isso não seria bom (LINS, 2012, p. 12, grifos do autor).

Além disso, como afirma Lins (2012, p. 13), "nenhum conhecimento vem ao mundo ingenuamente. Aquele que o produz, que o enuncia, já fala em uma direção (o interlocutor) na qual o que ele diz, e com a justificação que tem, pode ser dito".

Também, o conceito de "legitimidade" foi importante para a pesquisa. Não há como falar acerca de uma educação que valorize saberes marginalizados com enunciações distintas daquelas consideradas corretas em sala de aula, ou de saberes de comunidades marginalizadas, como é a do campo, foco deste trabalho - sem falar sobre legitimidades.

Para Lins (2012, p. 20),

[...] o que se internaliza não é o conteúdo, não são conceitos, e sim legitimidades: a pessoa já era capaz de fazer; mas não sabia que nesta ou naquela situação aquilo era legítimo, que nesta ou naquela situação aquele modo de produção de significado era legítimo. [...] Internalizar interlocutores, legitimidades, é o que torna possível a produção de conhecimento e significado, torna possível antecipar uma legitimidade do que digo.

Desse modo, estabelecemos uma relação entre a Etnomatemática e o Modelo dos Campos Semânticos. A Etnomatemática parece ter dado, por meio das pesquisas realizadas e do campo que abriu, legitimidade a outros modos de produção de significado para aquilo que se chama matemática.

Diante das opções teóricas e metodológicas da pesquisa, não podíamos iniciar as visitas com um Produto Educacional já pronto, com algo a ser desenvolvido em aulas de Matemática, por exemplo. Entendemos que precisaríamos viver aquela realidade, compreender suas complexidades e, depois, se fosse o caso, poderíamos propor algo. 
Foi desse modo, portanto, que surgiu o livreto de crônicas ${ }^{7}$. Foi uma alternativa por nós encontrada. Como afirma Ewald (1993, p. 26 apud VEIGANETO, 1996, p. 31), "nada de imposições, uma possibilidade entre outras; certamente que não mais verdadeira que as outras, mas talvez mais pertinente, mais eficaz, mais produtiva...".

O período mais intenso de visitas à escola e o aprofundamento nas discussões teóricas e metodológicas levaram-nos a essa escolha. Quisemos pensar em algo que fosse uma contraconduta (FOUCAULT, 2008), uma vontade de potência (NIETZSCHE, 2010), que fomentasse a produção do novo, a negação do dito e feito, que possibilitasse outros olhares e performances. É isso que esperávamos - e ainda esperamos - com esse Produto Educacional: professores que lessem as crônicas e (re)criassem suas práticas, a partir de suas próprias conclusões após a leitura de nossas inquietações!

E é isso que importa: não produzir algo de verdadeiro, no sentido de definitivo, absoluto, peremptório, mas dar "peças" ou "bocados", verdades modestas, novos relances, estranhos, que não implicam silêncio de estupefação ou um burburinho de comentários, mas que sejam utilizáveis por outros como as chaves de uma caixa de ferramentas (EWALD, 1993, p. 26 apud VEIGA-NETO, 1996, p. 31).

Em seguida, apresentamos algumas dessas inquietações propiciadas pela pesquisa realizada, mescladas com crônicas presentes no Produto Educacional.

\section{Seguindo a leitura}

As questões relacionadas à infraestrutura estiveram sempre muito presentes em nossa vivência na escola. Um primeiro ponto refere-se às condições de acesso - tanto para os professores como para os estudantes.

Os 10 quilômetros de estrada de terra que separam a área urbana do distrito de Lerroville da escola estão sempre com áreas problemáticas, podendo causar dificuldades no transporte, como furar um pneu, ou até atolar, em caso de chuva. Isso interfere diretamente na rotina dos professores - que precisam estar

${ }^{7}$ Agradecemos ao professor Roger Miarka por apresentar essa sugestão no momento do exame de qualificação da pesquisa de mestrado. Nas palavras de Ewald (1993, p. 26 apud VEIGA-NETO, 1996, p. 31), esse formato se mostrou muito "pertinente", "eficaz" e "produtivo". 
atentos, por exemplo, se o tempo está para chuva e se é preciso correr para conseguir ir embora.

Os estudantes também sentem esse problema, pois, pelo fato de 0 assentamento ser muito grande - somando as áreas dos Assentamentos Eli Vive I e Eli Vive II resulta em 7.312 hectares -, dependem também do transporte escolar para chegar à escola, sendo que muitos têm que andar algumas distâncias a pé, pois o ônibus não acessa algumas áreas. Há, ainda, casos de crianças em idade escolar que não frequentam a escola justamente por esse motivo.

A escola - que tem uma arquitetura bastante diferente do comum, com 22 salas que são espécies de casinhas de madeira dispostas em círculo - foi construída pelos próprios assentados, com materiais cedidos por outras escolas itinerantes. Alguns problemas decorrentes disso são: frestas entre as madeiras, que deixam com que a chuva entre nas salas; rede elétrica bastante instável, fazendo com que as salas sejam muito escuras, sem ventiladores (há professores que levam os seus de casa, mas não é possível que haja um em cada sala, pois a rede elétrica não suporta); não há rede de esgoto; constantes falhas no fornecimento de água, precisando, muitas vezes, recorrer a caminhões pipas para que haja água nos banheiros e para o preparo da merenda; falta de um espaço adequado para a prática de atividades físicas.

Em um dia de observação, algumas redações foram nos cedidas pela professora de Português. O tema da redação era "Minha escola é..." e foram realizadas por estudantes do $8^{\circ}$ e do $9^{\circ}$ ano do Ensino Fundamental. A ideia era apresentar os pontos positivos e negativos da escola sob a perspectiva dos estudantes. A questão acerca da precariedade da estrutura física foi quase uma unanimidade. Também, ficou evidente que, apesar de todas as dificuldades, os alunos se veem, como de fato são, parte do ambiente escolar. Entendem que aquele local pertence a eles.

Crônica 3: A Chuva 
Fazia cerca de uma semana que eu estava trabalhando na escola quando aconteceu pela primeira vez. Eu ainda não havia me acostumando com a dinâmica da escola, mas, aos poucos, ia me adaptando ao novo ambiente de trabalho, àquela rotina.

Naquele dia, havia um murmurinho entre os alunos sobre a possibilidade de irem embora mais cedo da aula. Confesso que fiquei sem entender. Imaginei que seria alguma dinâmica da escola, que eu não sabia, por ser novata ali, mas, como o diretor e o coordenador não haviam me passado nada, segui para a sala de aula normalmente. Era a $2^{2}$ aula do período da tarde, para uma turma de cerca de 12 alunos do $1^{\circ}$ ano do Ensino Médio. Logo que cheguei, surgiram diversos questionamentos sobre mim, antes mesmo que me apresentasse. As perguntas versavam sobre como havia ido parar ali, naquela escola, de onde eu estava vindo, se a professora que eu estava substituindo voltaria ou se eu assumiria até o fim do ano, se eu passava tarefa e coisas assim. Após respondê-las, uma nova pergunta surgiu:

- Que horas vão liberar a gente pra ir embora?

Imediatamente respondi que acreditava que seria no horário normal, às 17h40, pois ninguém havia me passado outra informação. Foi quando um dos alunos disse alto, claro e com um certo ar de tensão:

- Mas vai chover, fessora!

De imediato respondi:

- Uai, gente, mas chuva é lá motivo para não se ter aula?

A resposta veio na hora, de diversas bocas:

- Claro que é psora! Olha lá, já tá garoando.

- Vai vir chuva professora, um temporal, eu preciso ir pra casa.

- Psora! Vou ter que ir embora a pé se chover muito, como vou subir com a moto naquelas pedreiras lá?

No início, eu não estava entendendo tanta preocupação com a chuva. É só uma chuva, gente! Nem estava tão forte assim, quem disse a ele que ia vir um temporal? Mas aí começou a gotejar dentro da sala de aula, pois, como as salas 
são feitas de madeira, há algumas frestas entre as tábuas, e os alunos começaram a desviar suas carteiras das goteiras.

Quando um dos alunos disse sobre "passar com a moto nas pedreiras", vieram duas coisas à mente. A primeira foi o fato de não entender como um aluno que não tem mais do que 16 anos havia ido à escola de moto, sendo que não tem nem idade para ter carteira de habilitação. Depois de algum tempo, percebi que isso era uma prática normal entre os alunos do Ensino Médio. A segunda coisa que me chamou a atenção foi a estrada. Se já é extremamente difícil percorrer 0 caminho quando não chove, será que a van consegue atravessar aqueles buracos, subidas e descidas com chuva?

Após uns 20 minutos do início da aula, a chuva apertou. Começou a chover muito forte, e então os alunos foram liberados para que corressem para os ônibus. Caso eles ficassem mais alguns minutos na escola, provavelmente os ônibus não conseguiriam percorrer o trajeto necessário. Como os alunos foram dispensados, nós, professores, também fomos.

Foi uma correria que só! Os alunos correndo em direção aos ônibus em meio à chuva, os professores correndo para a sala dos professores para pegar seus materiais.

- Pega tudo rápido, se não a gente não chega em casa hoje!, disse uma das professoras.

Fiquei tensa com aquela frase. Como assim, não vou chegar em casa hoje? Tentei ir o mais rápido que pude. Passei na sala dos professores, peguei meu lanche na geladeira, juntei meu material e, quando fui sair da sala dos professores, levei um tombo na escada! Foi lama para todo lado. Fingi que nada tinha acontecido, levantei rápido e fui em direção à van. Saímos da Escola por volta das 14h15, e aquele caminho, que já não era fácil, ficou três vezes pior, mas, apesar da dificuldade, conseguimos atravessar a estrada de terra sem atolar. Chegamos à cidade às $15 \mathrm{~h} 40$ e só quando já estava em casa percebi que havia aberto o pulso quando caí. 
Costumo dizer que cada dia de trabalho lá na escola é uma aventura. Nunca sabemos como vai ser o nosso dia ou a hora em que voltaremos para casa, só se sabe que a aventura estará garantida. A chuva é a solução para os moradores do assentamento, visto que a maioria trabalha com a plantação em seus lotes, mas, para que as aulas aconteçam, ela se torna um grande e difícil problema.

Ser professor em uma escola como essa sempre foi, para nós, uma inquietação. Quem são os professores? Eles têm formação específica para lidar com o que há de específico nessa escola? Educação do Campo é um tema comum a eles? Eles conhecem a proposta curricular das escolas itinerantes? Como planejam suas aulas, levando em conta todos esses pontos?

Durante a pesquisa, notamos que havia uma diferença entre os professores da Educação Infantil e do Ensino Fundamental I - da Escola Municipal do Campo Trabalho e Saber - e os professores do Ensino Fundamental Il e do Ensino Médio - do Colégio Estadual Maria Aparecida Rosignol Franciosi. Os primeiros eram denominados de "educadores" e os segundos de "professores". Os chamados educadores, até o ano de $2016^{8}$, eram professores assentados. Eram professores que conheciam a Educação do Campo, a maioria tendo sua formação inicial em cursos específicos, sabiam qual era a proposta curricular das escolas itinerantes e procuravam implementá-las em suas práticas pedagógicas. Já os demais eram professores PSS, em sua maioria residentes na sede do município de Londrina, que desconheciam a proposta das escolas itinerantes e a própria Educação do Campo.

O Plano de Estudos aborda esse ponto e diz que "conhecer o meio no qual vive a juventude (local, nacional e internacional) é [...] base para aqueles que conduzem a formação da juventude em uma dada escola. Mas conhecer não

${ }^{8}$ A partir do ano de 2017, com o processo de municipalização da Educação Infantil e do Ensino Fundamental I, a maior parte dos professores desses níveis também deixou de ser do assentamento e foi contratada por meio de contratos temporários. 
basta, tem que haver cumplicidade" (MOVIMENTO DOS TRABALHADORES RURAIS SEM TERRA, 2013, p. 23).

Diante disso tudo, como será que aconteciam os complexos de estudo, em particular, no Ensino Fundamental II e no Ensino Médio? Conversando com o coordenador, perguntamos isso a ele, principalmente porque não havia um momento de planejamento conjunto entre os professores, considerando que a proposta é interdisciplinar. De acordo com o Plano de Estudos, deveria haver um calendário anual com os "tempos dos educadores", para esse tipo de preparação. Sua resposta foi que, por diversas razões, e dentre elas o fato de não conseguirem um momento em que os professores consigam se reunir para a elaboração de propostas, cada professor era responsável por tentar, de alguma forma, incorporar os complexos em sua dinâmica.

Percebemos, no dia da primeira visita, quando fomos conhecer a escola, que no Ensino Fundamental I a situação era um pouco diferente. Presenciamos uma reunião entre dois professores que planejavam atividades conjuntas e eles nos explicaram que estavam trabalhando com os complexos de estudo.

Ao participarmos das aulas de Matemática, procuramos compreender como isso acontecia. A professora, que aceitou nossa participação, inclusive com a gravação em áudio de todas essas aulas, era contratada pelo PSS, licenciada em Química e estava substituindo outra professora, que se encontrava em licença maternidade. Notamos, porém, que os complexos de estudo não estavam presentes nas aulas. Por isso, em um dado momento, conversamos sobre isso com a professora. Ela disse que "já havia ouvido falar", mas que "nunca parou para ver" a proposta curricular presente no Plano de Estudos.

Segundo ela, mal consegue preparar as aulas normalmente, o que dirá pesquisar outra realidade. Durante a conversa, ela disse que acorda às 5h30 para conseguir pegar a van dos professores às $6 \mathrm{~h} 30$ e ir para a escola, permanece o dia todo lá e chega em Londrina por volta das 19h. Quando chega, precisa fazer janta para seu marido e filho pequeno, ajudar com os deveres da escola, limpar a casa, preparar o almoço e lanche para seu filho levar à escola no dia seguinte e 
também para ela levar à escola. E aí ela perguntou: Quando que eu consigo parar para fazer isso?

Nas escolas públicas estaduais do Paraná, sabemos que os professores precisam assumir uma grande quantidade de aulas para que obtenham um salário compatível com suas necessidades - o que acaba interferindo no tempo disponível para a preparação das aulas. No caso das escolas itinerantes, que possuem uma proposta metodológica específica, isso se torna um problema ainda maior, pois exigiria um tempo extra para estudo e planejamento.

Outro ponto que acaba dificultando a realização das propostas das escolas itinerantes é a rotatividade de professores. Com os contratos temporários, não há garantia de que um professor voltará àquela escola no ano seguinte. Nessa escola, por exemplo, diversos professores que lá lecionavam em 2016 não continuaram em 2017. Alguns optaram por permanecer em Londrina, devido à distância, e outros não conseguiram continuar na escola, devido à pontuação obtida na seleção. Consequentemente, no novo ano, novos professores chegaram.

Crônica 11: PSS não tem vez

Acredito que essa seja a crônica mais difícil de escrever, até agora. Eu nunca fui boa com despedidas. No início, foi muito (e quando eu digo muito, quero dizer muito mesmo) difícil me adaptar à realidade e à dinâmica da nova escola. Madrugar para pegar a van, a falta de estrutura, contexto totalmente diferente daquele a que eu estava acostumada, ter que preparar marmitas, me adaptar com a estrada, os ratos, ficar atolada por causa da chuva. Enfim, não foi nada fácil.

Mas, por outro lado, foi um grande aprendizado passar por todas essas situações. Principalmente no que diz respeito à minha prática docente. Antes, eu ligava o botãozinho do automático e ia, como se fosse um carro desgovernado. Não pensava muito sobre quem estava na minha frente, agia sempre da mesma maneira. 
Após alguns anos de carreira, precisei sair da minha zona de conforto para poder descobrir uma nova forma de lecionar. Depois que me propus a trabalhar de uma maneira diferente do que fizera durante toda a minha vida, que refleti sobre a minha prática, criei um "bichinho" dentro de mim que tem necessidade de tentar trabalhar com a realidade que interessa aos meus alunos. Esse bichinho ainda é filhote, também está em fase de aprendizagem, feito criança que está aprendendo andar e falar. Às vezes ele leva uns tombos, faz umas coisas erradas, mas tem se levantado, persistido, tentado.

Mas não é algo simples alimentá-lo. É necessário tempo para elaborar as propostas e um ouvido sempre alerta pelos corredores da escola, em busca de situações ou falas que despertem nele a vontade de tentar de novo, mesmo sabendo que corre o risco de levar um outro tombo.

Eu ainda não consegui formá-lo a ponto de utilizá-lo em todas as aulas. Acho que isso se deve à falta de tempo, à quantidade de turmas e à falta de conhecimento sobre aquela realidade. Mas ele está aqui. Sempre alerta. Em busca de novas oportunidades de se desenvolver e tentar algo novo. Confesso que ele já me deixou em algumas situações complicadas, fazendo sair totalmente do planejado, mas, depois que passa a tensão, eu não fico brava com ele não. Acho que aí é que está o segredo da nossa aprendizagem, só saberemos fazendo. Só aprimoraremos nossas propostas com base no que não deu certo, na prática. Afinal, o que é matemática, senão movimento?

Então, fazendo um balanço de toda a experiência deste ano, acredito que foi um ano de aprendizado. De alguns tapas na cara para mostrar que o professor não é o detentor absoluto do conhecimento, e que os alunos, seus pais e toda a comunidade escolar também podem contribuir com o processo de ensino e aprendizagem.

Confesso que, apesar de todas as dificuldades, esses últimos meses na escola me fizeram querer voltar para dar aulas lá no ano que vem. Mas é aquele famoso ditado, não é? Querer não é poder! Sou professora PSS, não depende de mim. Depende da pontuação. Depende da classificação. Depende da 
convocação. Ano que vem? É outro ano. Outro contrato. Provavelmente, outra escola.

E por que todas essas crônicas? Bom, quem sabe para dividir com os novos professores que, assim como eu, irão "cair de paraquedas" lá na escola. Talvez elas possam ajudá-los de alguma maneira. Quem sabe eles tentem criar esse tal bichinho dentro de si mais cedo do que eu, que o criei nos meus últimos meses de escola? Ou, sei lá, talvez não, talvez seja só a necessidade de desabafar. O que eu sei é que sinto a necessidade de alimentar esse bichinho que há dentro de mim, onde quer que eu vá. Como farei? Onde farei? Isso eu ainda não consigo responder, pois, como já foi dito, professor PSS não tem vez. Não depende de mim. Teremos que aguardar.

Essas muitas vivências e inquietações nos fizeram criar as crônicas fictícias, mas com doses de realidade.

Como descrito por relatório do Instituto Nacional de Estudos e Pesquisas Educacionais Anísio Teixeira (INEP), sobre a Educação do Campo, entre outros problemas, está "a falta de professores habilitados e efetivados, o que provoca constante rotatividade" e "baixos salários e sobrecarga de trabalho dos professores, quando comparados com os dos que atuam na zona urbana" (INSTITUTO NACIONAL DE ESTUDOS E PESQUISAS EDUCACIONAIS ANÍSIO TEIXEIRA, 2007, p. 8-9). Desse modo, todo ano, novos professores chegam a essas escolas do campo - não somente às escolas itinerantes -, por meio de contratos temporários, causando um ciclo interminável de estranhamento, habituação, adaptação (e até possível incorporação da proposta da educação do campo), novos professores, estranhamento novamente e assim por diante.

Pensamos, portanto, em direcionar os textos a esses professores e, para isso, a criação da personagem Maria - nessa mesma situação de professora temporária. 


\title{
4 Colocando o livro na estante
}

Fugir de recomendações a professores, dizendo a eles como agir ou não em suas aulas, foi uma busca presente em nossa pesquisa. Em termos de Foucault (2008), uma contraconduta, "no sentido de luta contra os procedimentos postos em prática para conduzir os outros" (p. 266). Contraconduta na tentativa de não apresentar algo direcionador, fruto da pesquisa científica, aos professores, do alto da academia àqueles que vivem o chão da escola. Não conduzir - essa foi a ideia.

As crônicas, de uma personagem não real, não dizem sobre a verdade, mas sobre uma, que é transitória, que nem ela mesma tem certeza sobre o que diz. Mas elas propõem um pensar sobre escolhas feitas por uma professora, que se vê insegura com as mudanças que vive, em um mundo diferente do seu - ou seria o seu mundo diferente daquele que vive? Maria reflete sobre isso, a diferença, em uma de suas crônicas.

Potência para agir, criar, inventar, reinventar, questionar, duvidar - é isso que almeja o livreto de crônicas. Que ele seja vontade de potência:

\begin{abstract}
Vontade no sentido de um aquém e de um além de qualquer pessoal. Forças livres, anônimas, pululantes, em luta, apenas linhas de composição produzindo movimentos de expansão, apropriações recíprocas, transmutações, destruição e criação continuada e infinita de formas, dobras, desdobras fugazes e moventes... Potência (muitas vezes também traduzida e compreendida como Poder) implica e aponta o que constitui a Vontade, a saber, o que não para de pulsar, desdobrar-se, buscar expansão, vida... Assim, quando se perspectiva o real imanentemente segundo essa cosmologia, a Potência é criadora: criadora de mundos, criadora de subjetividades, criadora de aulas, criadora de currículos, criadora de vida... Uma cosmologia criadora de valores, de um mundo, de uma vida (CLARETO; NASCIMENTO, 2012, p. 315, grifos dos autores).
\end{abstract}

Fechar o livro, colocá-lo na estante e viver: essa é a potencialidade (e a limitação) do nosso Produto Educacional.

\section{Referências}

ALTRICHTER, Herbert; HOLLY, Mary Louise. Diários de Pesquisa. In: SOMEKH, Bridget; LEWIN, Cathy. (Org.). Teoria e métodos de pesquisa social. Petrópolis: Vozes, 2015. p. 79-89. 
BORGES, Larissa Gehrinh. Saberes matemáticos nas escolas itinerantes: complexos de estudos. 2017. 118 f. Dissertação (Mestrado em Ensino de Matemática) - Universidade Tecnológica Federal do Paraná, Londrina, 2017.

CALDART, Roseli Salete et al. (Org.). Dicionário da Educação do Campo. Rio de Janeiro, São Paulo: Escola Politécnica de Saúde Joaquim Venâncio, Expressão Popular, 2012.

CLARETO, Sônia Maria; NASCIMENTO, Luiz Alberto Silvestre do. A sala de aula e a construção de um currículo-invenção. Currículo sem fronteiras, v. 12, n. 3, p. 306-321, set./dez. 2012.

COLÉGIO ESTAdUAL MARIA APARECIDA ROSIGNOL FRANCIOSI. Projeto PolíticoPedagógico. Londrina, 2015.

FOUCAULT, Michel Segurança, território, população: curso dado no Collège de France (19771978). Tradução de Eduardo Brandão. São Paulo: Martins Fontes, 2008

FREITAS, Luiz Carlos de. A luta por uma pedagogia do meio: revisitando o conceito. In: PISTRAK, Moisey Mikhaylovich. A Escola-Comuna. Tradução de Luiz Carlos de Freitas e Alexandra Marenich. São Paulo: Expressão Popular, 2009. p. 9-101.

GARNICA, Antonio Vicente Marafioti. História oral em educação matemática: um panorama sobre pressupostos História Oral. História Oral, v. 18, n. 2, p. 35-53, jul./dez. 2015.

INSTITUTO NACIONAL DE ESTUDOS E PESQUISAS EDUCACIONAIS ANÍSIO TEIXEIRA. Panorama da educação do campo. Brasília: Instituto Nacional de Estudos e Pesquisas Educacionais Anísio Teixeira, 2007.

KNIJNIK, Gelsa. Etnomatemática e politicidade da Educação Matemática. In: CONGRESSO BRASILEIRO DE ETNOMATEMÁTICA, 1., 2000, São Paulo. Anais... São Paulo, 2000.

LINS, Romulo Campos. O Modelo dos Campos Semânticos: estabelecimentos e notas de teorizações. In: ANGELO, Claudia Laus et al. (Org.) Modelo dos Campos Semânticos e Educação Matemática: 20 anos de história. São Paulo: Midiograf, 2012. p. 11-30.

MOVIMENTO DOS TRABALHADORES RURAIS SEM TERRA. Escola Itinerante: Plano de Estudos. Cascavel: UNIOESTE, 2013.

NIETZSCHE, Friedrich Wilhelm. Vontade de Potência. Petrópolis: Editora Vozes. 2011.

SACHS, Línlya. Teorias curriculares e implicações pedagógicas da etnomatemática no contexto da educação do campo. In: SILVA, Karina Aparecida Pessoa; DALTO, Jader Otavio. (Org.) Educação Matemática e Pesquisa: algumas perspectivas. São Paulo: Livraria da Física, 2017. p. 297-318.

SAPELLI, Marlene Lucia Siebert; FREITAS, Luiz Carlos de; CALDART, Roseli Salete. (Org.) Caminhos para transformação da Escola: organização do trabalho pedagógico nas escolas do campo: ensaios sobre complexos de estudo. São Paulo: Expressão Popular. 2015.

VEIGA-NETO, Alfredo. Olhares... In: COSTA, Marisa Vorraber (Org.) Caminhos Investigativos. Porto Alegre: Mediação, 1996. p. 19-35. 